\title{
A complex mTOR response in habituation paradigms for a social signal in adult songbirds
}

\author{
Somayeh Ahmadiantehrani, Elisa O. Gores, and Sarah E. London \\ Department of Psychology, Institute for Mind and Biology, Grossman Institute for Neuroscience, Quantitative Biology \\ and Human Behavior, University of Chicago, Chicago, Illinois 60637, USA
}

\begin{abstract}
Nonassociative learning is considered simple because it depends on presentation of a single stimulus, but it likely reflects complex molecular signaling. To advance understanding of the molecular mechanisms of one form of nonassociative learning, habituation, for ethologically relevant signals we examined song recognition learning in adult zebra finches. These colonial songbirds learn the unique song of individuals, which helps establish and maintain mate and other social bonds, and informs appropriate behavioral interactions with specific birds. We leveraged prior work demonstrating behavioral habituation for individual songs, and extended the molecular framework correlated with this behavior by investigating the mechanistic Target of Rapamycin (mTOR) signaling cascade. We hypothesized that mTOR may contribute to habituation because it integrates a variety of upstream signals and enhances associative learning, and it crosstalks with another cascade previously associated with habituation, ERK/ZENK. To begin probing for a possible role for $\mathrm{mTOR}$ in song recognition learning, we used a combination of song playback paradigms and bidirectional dysregulation of $\mathrm{mTORCl}$ activation. We found that mTOR demonstrates the molecular signatures of a habituation mechanism, and that its manipulation reveals the complexity of processes that may be invoked during nonassociative learning. These results thus expand the molecular targets for habituation studies and raise new questions about neural processing of complex natural signals.
\end{abstract}

Nonassociative learning is often considered a simple type of learning, as it is dependent on presentation of a single stimulus. One form of nonassociative learning, habituation, is characterized by a response decrement that results from repeated stimulation and that does not involve sensory adaptation or fatigue (Thompson and Spencer 1966; Rankin et al. 2009). Importantly, habituation is not simply loss of response, but a functional gain of discriminatory ability between similar stimuli. It is thus an important form of learning for individuals within dynamic environments. Indeed, its traits are conserved and consistent across a wide span of animal models and paradigms (Thompson and Spencer 1966; Giles and Rankin 2009; Rankin et al. 2009). Habituation is far from simple, however. Ten criteria have been proposed to fully describe habituation, and despite investigation at multiple levels including molecular, cellular, and population measures in the brain, as well as outcomes of behavior and physiology across species, we still do not have a comprehensive mechanistic understanding to explain its underlying complexity (Leussis and Bolivar 2006; Rankin et al. 2009).

Adult song recognition learning in songbirds is an ethologically relevant framework for mechanistic examination of nonassociative learning. For example, in colonial zebra finches (Taeniopygia guttata), each male sings one unique song his entire adult life. Recognition of specific songs can thus be used for individual identification, even when the bird is out of sight. Song carries social information that is used to establish and maintain relationships (Woolley and Doupe 2008; Riebel 2009; Lin et al. 2014). Song habituation would therefore support appropriate behavioral interactions with mates and neighbors versus intruders.

Studies using song playback training paradigms reveal that zebra finch song recognition exhibits several key criteria for habituation. Behaviorally, adult zebra finches show longer durations of "quiet listening" responses when hearing novel songs compared

Corresponding author: london@uchicago.edu

Article is online at http://www.learnmem.org/cgi/doi/10.1101//m.046417.117. to songs they experienced $24 \mathrm{~h}$ earlier (Stripling et al. 2003; Dong and Clayton 2008). Invasive procedures disrupt this behavioral response, but in unmanipulated birds, molecular and physiological brain measures show reliable correlations with quiet listening durations, providing support that the neural responses reflect behaviorally relevant habituation processes (Stripling et al. 2003; Dong and Clayton 2008; Lin et al. 2014). Further, molecular responses to repeated auditory stimuli are not sensory or perceptual, rather categorical, and neuroanatomically restricted to higherorder processing areas in the auditory forebrain, called the caudomedial nidopallium (NCM) and caudomedial mesopallium (CMM; Mello et al. 1995; Rankin et al. 2009). The level of response is graded depending on biological relevance, stimulus novelty, and the context in which a song is experienced, following habituation curves described in other animals (Thompson and Spencer 1966; Mello et al. 1995; Kruse et al. 2004; Giles and Rankin 2009), and attenuated responses are "rescued" by presentation of a distinct novel song (Mello et al. 1995). Neurophysiological measures also demonstrate response properties typical of habituation in other models (Chew et al. 1995; Stripling et al. 1997, 2003). As in other systems, habituation in adult zebra finches recruits a suite of genes that distinguishes it molecularly from those invoked upon hearing the initial song presentations (Dong et al. 2009). These findings are based on controlled laboratory playback paradigms but likely represent noncaptive responses (McKenzie et al. 2006).

Here, we were motivated to expand our understanding of the molecular underpinnings involved in nonassociative song recognition learning. We focused on the mechanistic Target of Rapamycin (mTOR) signaling cascade. mTOR is appealing as a mediator of nonassociative learning because it integrates multiple

(C) 2018 Ahmadiantehrani et al. This article is distributed exclusively by Cold Spring Harbor Laboratory Press for the first 12 months after the full-issue publication date (see http://learnmem.cshlp.org/site/misc/terms.xhtml). After 12 months, it is available under a Creative Commons License (AttributionNonCommercial 4.0 International), as described at http://creativecommons. org/licenses/by-nc/4.0/. 
upstream signals of the environment and is activated by triggers of experience-dependent plasticity (Hoeffer and Klann 2010; Costa-Mattioli and Monteggia 2013). mTOR, as a core member of mTOR complex 1 (mTORC1), can mediate synaptic plasticity by regulating mRNA-to-protein translation (Cammalleri et al. 2003; Kelleher et al. 2004; Richter and Klann 2009; Costa-Mattioli and Monteggia 2013). mTOR signaling makes demonstrated contributions to learning and memory but very little is known about its role in nonassociative learning (Hoeffer and Klann 2010; CostaMattioli and Monteggia 2013; Fifield et al. 2013; Graber et al. 2013; Fortress et al. 2015). We have, however, recently discovered that mTOR signaling in the auditory forebrain is required for tutor song copying in juvenile zebra finches (Ahmadiantehrani and London 2017). We therefore asked if mTORC1 signaling displayed signatures of nonassociative learning mechanisms in adults.

Toward this goal, we used the same 3-d-song playback paradigm previously shown to elicit distinct molecular and behavioral responses to familiar and novel song (Dong and Clayton 2008). We measured mTORC1 activation after varying training song experiences, and performed transient, bidirectional pharmacological manipulations of cascade activation within the auditory forebrain. We predicted that both constitutive activation and inhibition would disrupt nonassociative learning, as occurred for juvenile song learning (Ahmadiantehrani and London 2017). Further, most prior work associating molecular readouts with behavioral outcomes of the song habituation paradigm examined either Extracellular signal Regulated Kinase (ERK) or ZENK (zif268, egr-1, ngfi-a, krox24) signaling as a readout. These measures are functionally linked-transcription of the immediate early gene ZENK depends on ERK phosphorylation (pERK) - we will therefore use "ERK/ZENK" signaling when referencing learning outcomes from either measure (Mello et al. 1995; Cheng and Clayton 2004; Kruse et al. 2004; Dong and Clayton 2008; London and Clayton 2008; Dong et al. 2009). Notably, ERK signaling is also required for juvenile song learning and the mTOR and ERK cascades crosstalk (London and Clayton 2008; Gobes et al. 2010; Mendoza et al. 2011). We therefore predicted that mTORC1 would display the habituation-typical response patterns, mirroring those of ERK/ZENK. Results from the current series of experiments suggest that, like most complex processes, song recognition learning may be more fully understood with consideration of several molecular cascades. Our data implicate mTORC1 in adult song recognition learning in ways that are dissociable from ERK/ZENK, revealing new paths for investigation into possible mechanisms of nonassociative learning of complex natural signals.

\section{Results}

\section{mTORCl cascade proteins are present in the adult zebra finch auditory forebrain}

The presence of essential proteins for mTORC1 signaling had not been previously reported in adult songbirds (Acharya and Veney 2013). Here, under baseline conditions, key complex 1 cascade proteins mTOR, ribosomal S6 protein kinase (S6K), and the $40 \mathrm{~S}$ subunit ribosomal S6 protein (S6), were readily detectable in lysates of the auditory forebrain of adult male and female zebra finches (Fig. 1A,B). Each antibody revealed specific protein bands of the expected size. When band intensities were normalized to the housekeeping enzyme glyceraldehyde-3-phosphate dehydrogenase (GAPDH) loading control, we detected no effect of Sex for any mTOR cascade protein (mTOR: $F_{(1,6)}=3.6, P=0.11$, SK6: $F_{(1,6)}=2.34, P=0.18, \mathrm{~S} 6: F_{(1,6)}=3.21, P=0.12$ ) (Fig. $1 \mathrm{C}$ ). When normalized to the mature neuron marker NeuN, there were no sex differences in S6K $\left(F_{(1,6)}=0.59, P=0.47\right)$ or S6 $\left(F_{(1,6)}=1.01, P=0.35\right)$, but there was a significant sex difference for $\operatorname{mTOR}\left(F_{(1,6)}=14.85\right.$,
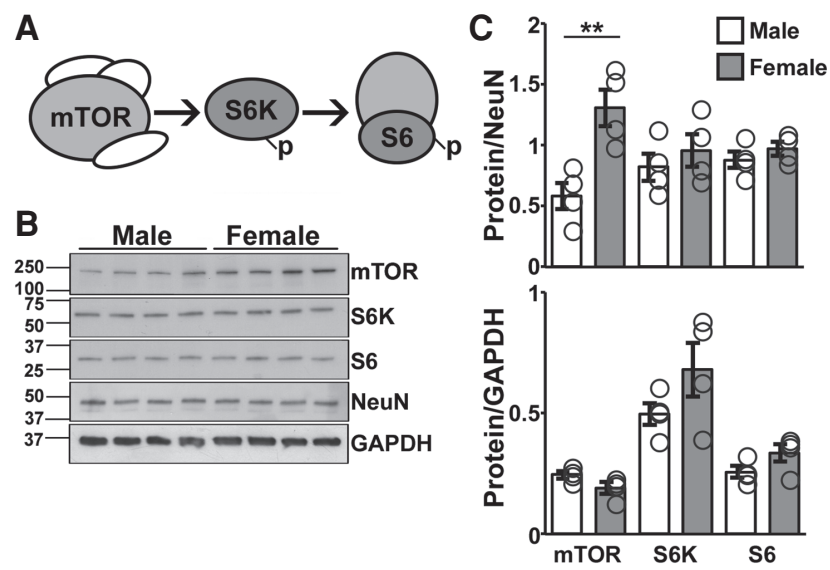

Figure 1. Key proteins in the mTOR-S6K-S6 signaling cascade are present in the adult zebra finch auditory forebrain. $(A)$ Schematic depicting the relationship between mTORC1, S6K, and S6. (p) phosphorylation. $(B)$ Immunoblot with male and female auditory forebrain samples shows bands of the expected molecular weight for mTOR, S6K, S6, NeuN, and GAPDH. Precedence for a double band pattern for NeuN has been noted by the manufacturer (www.emdmillipore.com). $n=4$ males and 4 females. (C) NeuN- and GAPDH-normalized protein ratios. Bars represent the experimental group mean \pm SEM. Circles denote the individual birds in each experimental group. Group means \pm SEM for NeuN-normalized mTOR: $0.58 \pm 0.11$ (males) and $1.31 \pm 0.15$ (females); S6K: $0.82 \pm 0.11$ (males) and $0.96 \pm 0.14$ (females); S6: $0.88 \pm 0.069$ (males) and $0.97 \pm 0.058$ (females). Group means \pm SEM for GAPDH-normalized mTOR: $0.28 \pm 0.016$ (males) and $0.19 \pm 0.024$ (females); S6K: $0.50 \pm 0.045$ (males) and $0.68 \pm 0.11$ (females); S6: $0.26 \pm 0.024$ (males) and $0.34 \pm 0.037$ (females). ${ }^{* *} P<0.05$, for NeuN-normalized mTOR levels between males and females.

$P=0.008)$ (Fig. 1C), with females having relatively more abundant mTOR in neurons than males. For subsequent analysis, we used the ratio of phosphorylated (activated) S6 (pS6) to total S6 as a readout of mTORC1 activation.

\section{Experiment $1: \mathrm{mTORCl}$ is differentially activated depending on song familiarity}

We first asked if the mTORC1 cascade was activated in the adult auditory forebrain upon hearing song, and if the response depended on prior opportunity to learn that "training" song. We used an established 3-d-song recognition learning paradigm (Fig. 2; Chew et al. 1995; Mello et al. 1995; Stripling et al. 1997, 2003; Cheng and Clayton 2004; Dong and Clayton 2008; Dong et al. 2009). In this assay, the effectiveness of experience with training song is assessed $24 \mathrm{~h}$ post-training, when birds hear playbacks of either the training song again (Trained-Familiar), a new song (TrainedNovel), or no song (Trained-Silence) as a control for possible persistent effects of the training experience.

With pS6 and S6 immunohistochemistry, we observed that S6-positive (S6+) cells were evenly distributed throughout both auditory forebrain regions involved in higher-order auditory processing, NCM and CMM (Fig. 3A,B). In general, S6+ cells were more numerous in NCM than in CMM. In contrast, pS6-positive (pS6+) cells appeared as subpopulations within NCM and CMM. pS6+ cells were largely absent from primary auditory cortex, Field L (Wang et al. 2010; Dugas-Ford et al. 2012; Karten 2013).

For quantitation, we first confirmed there were no significant effects on cell densities in the adjacent hippocampus (HP; Sex $\left(\mathrm{pS6} 6\right.$ : $\left.F_{(1,12)}=0.14, P=0.71 ; \mathrm{S} 6+: F_{(1,12)}=0.004, P=0.95\right)$; Playback (pS6+: $F_{(2,12)}=0.78, P=0.48 ; \mathrm{S} 6+: F_{(2,12)}=0.58, \quad P=$ $0.57) ; \mathrm{Sex} *$ Playback (pS6+: $F_{(2,17)}=0.76, P=0.49 ; \mathrm{S} 6+: F_{(2,17)}=$ 


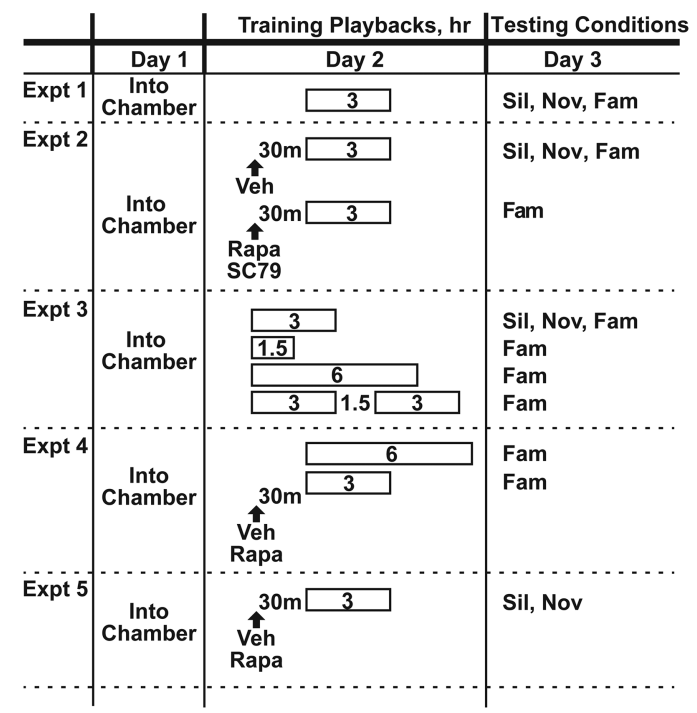

Figure 2. Schematic of 3-d-song recognition paradigm variations, including infusions, duration of training song playbacks, and testing song conditions, for the five experiments. Headers indicate song playback events on Days 2 and 3. Conditions for each experiment (Expt) are listed across the rows; a dashed line separates experiments. On Day 1, birds for all experimental groups were placed into acoustic isolation chambers. Training song playbacks on Day 2 varied in length depending on the experiment and group. Blocks illustrate duration of habituation training; the number within the block denotes the duration of training song playbacks in hours (h). Note Expt 3 has a group with a $1.5 \mathrm{~h}$ separation between two $3 \mathrm{~h}$ training song playbacks. Arrows indicate Rapamycin (Rapa), SC79, or DMSO (Veh) infusions 30 min prior to Day 2 training song playbacks. Testing conditions for pS6 activation on Day 3 included birds who experienced novel (Nov) or familiar (Fam) song playbacks for $30 \mathrm{~min}$, or who were left in silence (Sil) for control; these groups are labeled Trained-Novel, Trained-Familiar, Trained-Silence, respectively.

0.02, $P=0.98)$ ) to use for background staining normalization (Mello et al. 1992; Mello and Clayton 1994). After using HP to normalize pS6+ and S6+ cell densities, we further found no effect of Sex $\left(\mathrm{CMM}: F_{(1,12)}=0.218, P=0.42\right.$; NCM: $\left.F_{(1,12)}=0.364, P=0.26\right)$ or Sex * Playback condition interaction $\left(\mathrm{CMM}: F_{(2,17)}=1.102, P=\right.$ 0.67 ; NCM: $\left.F_{(2,17)}=0.814, P=0.24\right)$ on $\mathrm{pS} 6+/ \mathrm{S} 6+$ measures. We therefore combined male and female data for subsequent analyses.

We did find a significant main effect of song playback condition in both CMM and NCM (CMM: $F_{(2,15)}=81.92, P=8.5 \mathrm{E}^{-9}$; NCM: $\left.F_{(2,15)}=12.43, P=0.0007\right)$. Patterns of mTOR activation were consistent with habituation; post hoc Bonferroni revealed significantly higher $\mathrm{pS6+/S6+}$ cell density in the Trained-Familiar (CMM: $P=5.78 \mathrm{E}^{-5}$; NCM: $P=0.014$ ) and Trained-Novel groups (CMM: $P=5.36 \mathrm{E}^{-9}$; NCM: $\left.P=0.0006\right)$ compared with the Trained-Silence group (Fig. 3C). In CMM, there was also significantly greater $\mathrm{pS} 6+/ \mathrm{S} 6+$ cell density in the Trained-Novel group compared to the Trained-Familiar group (CMM: $P=2.26 \mathrm{E}^{-5}$; NCM: $P=0.42)$; NCM showed a trend for Trained-Familiar mTOR activation levels to be intermediate between those of both the Trained-Silence and Trained-Novel conditions (mean \pm SEM: Trained-Silence: $\quad 0.061 \pm 0.01$; Trained-Familiar: $\quad 0.18 \pm 0.024$; Trained-Novel: $0.24 \pm 0.035$ ).

\section{Experiment 2: mTOR inhibition alters the mTORC1 response to familiar song playbacks}

We then bidirectionally manipulated mTOR phosphorylation during training song experience to test if altering mTOR signaling during learning affects the profile of mTORC1 activation upon reexposure to the training song. For this experiment, we bilaterally infused drug or vehicle into the auditory forebrain 30 min prior to training song playback (Fig. 2). We infused DMSO vehicle for TrainedSilence, Trained-Novel, and Trained-Familiar groups to affirm that the cannulation and infusion procedures did not alter the nonmanipulated pattern of $\mathrm{pS} 6+/ \mathrm{S} 6+$ activation. Indeed, the DMSO-Silence group had significantly lower pS6+/S6+ cell densities than DMSONovel (CMM: $P=2.72 \mathrm{E}^{-5}$; NCM: $P=0.014$ ) and DMSO-Familiar (CMM: $P=0.043$; NCM: $P=0.022$ ) groups (Fig. $4 \mathrm{~A}, \mathrm{~B}$ ). Also in CMM, DMSO-Novel birds also had significantly greater cell density than DMSO-Familiar birds (CMM: $P=0.014$; NCM: $P=1$ ) (Fig. $4 \mathrm{~A}, \mathrm{~B}$ ).

Drug-treated birds were infused with Rapamycin, which inhibits mTOR activation, or SC79, which constitutively activates mTOR in zebra finches and other animals (Hietman et al. 1991; Laplante and Sabatini 2009; Jo et al. 2012; Ahmadiantehrani and London 2017). These birds were then exposed to the TrainedFamiliar condition to assess the molecular effects of mTOR manipulation during training experience. Balanced mTORC1 signaling in the auditory forebrain is required for developmental song learning in juvenile zebra finches, as well as learning and memory in other systems (Hoeffer and Klann 2010; Ahmadiantehrani and London 2017). We thus predicted that both Rapamycin and SC79 would disrupt learning during training song playback sessions, resulting in a Novel song-like magnitude of molecular response to hearing the training song again. pS6 and S6 immunohistochemistry analysis did show a significant effect of Drug Treatment in CMM and NCM $\left(C M M: F_{(4,15)}=25.29, P=0.0001 ; \mathrm{NCM}: F_{(4,15)}=9.98, P=\right.$ 0.001) (Fig. 4B). However, only the Rapamycin-Familiar group showed a significant difference compared to DMSO-Familiar group cell densities in CMM $(P=0.0006)$ and NCM $(P=0.004)$, with mTORC1 activation levels lower in the Rapamycin-Familiar condition compared to DMSO-Familiar. There was no significant difference in the pS6+/S6+ cell densities between SC79-Familiar and DMSO-Familiar groups in CMM $(P=1)$ or NCM $(P=1)$.

Visual inspection of cannula tracks indicated that all cannulas terminated within the auditory forebrain, with minimal effect of cannula placement on molecular results. Out of 60 possible correlations between injection site and $\mathrm{pS} 6+/ \mathrm{S} 6+$ cell densities (three-dimensional coordinates (medial-lateral, dorsal-ventral, and rostral-caudal), two hemispheres, two brain regions, and five experimental groups), only two resulted in a significant correlation between injection site and pS6+/S6+ cell density: the medial-lateral dimension in the left hemisphere NCM of the DMSO-Familiar group $\left(R^{2}=0.93, F_{(1,2)}=28.73, P=0.03\right)$, and the rostral-caudal dimension in the right hemisphere CMM of the DMSO-Familiar group $\left(R^{2}=0.94, F_{(1,2)}=28.87, P=0.03\right)$. Cannula from subsequent experiments were also confirmed to be targeted to the auditory forebrain but not further analyzed for positional effects based on these results.

We also performed immunohistochemistry for ZENK because it has been related directly to learning, and its patterns of induction have been previously correlated with behavioral measures of habituation in the same Trained-Silence, Trained-Familiar, and TrainedNovel paradigm we used here (Mello et al. 1995; Tischmeyer and Grimm 1999; Bozon et al. 2002; Dong and Clayton 2008; London and Clayton 2008). Further, despite the cross-talk between ERK and mTOR signaling cascades, Rapamycin and SC79 do not directly affect ERK activation (Hietman et al. 1991; Mendoza et al. 2011; Jo et al. 2012). Here, the density of ZENK+ cells was higher in the DMSO-Novel group compared to both the DMSO-Silence group (CMM: $P=6.89 \mathrm{E}^{-6}$ and NCM: $P=2.84 \mathrm{E}^{-5}$ ) and the DMSO-Familiar group (CMM: $P=0.0007$ and NCM: $P=$ 0.005) as expected (Mello et al. 1995; Dong and Clayton 2008). In contrast to mTORC1 activation, ZENK induction is unaltered by dysregulation of mTOR signaling (Fig. 4C). Neither Rapamycin nor SC79 infusions altered the densities of ZENK+ cells after hearing Familiar song playbacks in comparison to the 


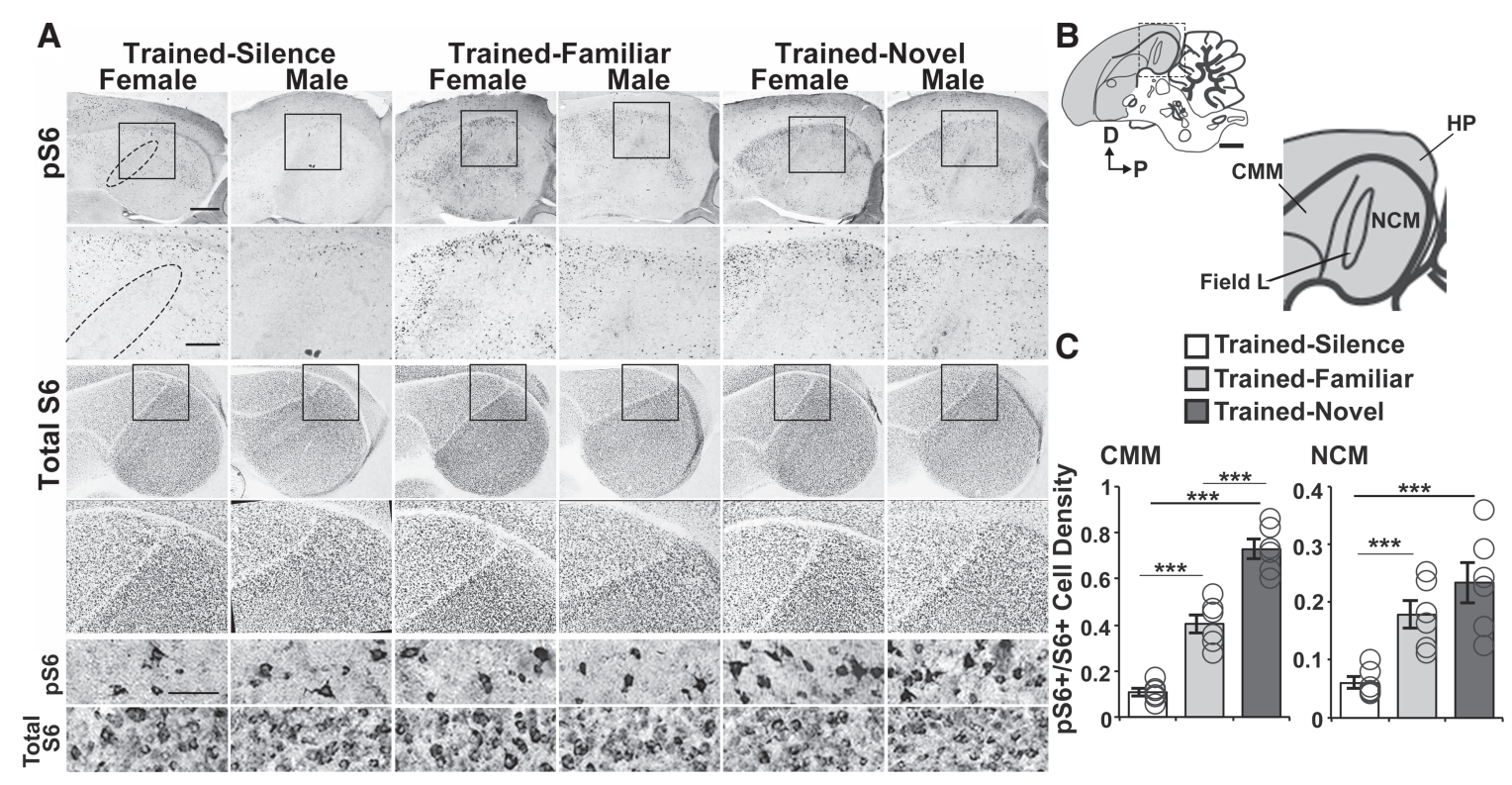

Figure 3. Levels of mTOR signaling cascade activation in the adult auditory forebrain depend on prior training song experience (Experiment 1 ). (A) Representative images of pS6 and total S6 immunostaining in male and female auditory forebrain in the Trained-Silence, Trained-Familiar, and Trained-Novel groups. Boxed insets of each image are shown in a higher magnification directly below. Field $\mathrm{L}$ is indicated with a dashed oval. Bottom two rows are high magnification images to show cellular specificity of the pS6 and total S6 immunostaining. Scale bars $=500 \mu \mathrm{m}$ (auditory forebrain), $250 \mu \mathrm{m}$ (boxed insets), and $25 \mu \mathrm{m}$ (high magnification images). (B) Sagittal schematic of the zebra finch brain, Dorsal (D) is up, Posterior (P) is to the right. Telencephalic regions are highlighted in gray. The area included in the auditory forebrain images in $A$ (indicated by dashed square) is enlarged to show neuroanatomical detail. Scale bar $=1 \mathrm{~mm}$. (CMM) caudomedial mesopallium; (NCM) caudomedial nidopallium; (HP) hippocampus. (C) pS6 $+/$ S6+ cell density ratios in the CMM (left) and NCM (right) in the three playback conditions. Bars represent the group mean \pm SEM. Open circles denote the individual birds. CMM group means \pm SEM: $0.11 \pm 0.015$ (Trained-Silence), $0.4 \pm 0.039$ (Trained-Familiar), and $0.73 \pm 0.042$ (Trained-Novel). NCM group means \pm SEM: $0.061 \pm 0.01$ (Trained-Silence), $0.18 \pm 0.024$ (Trained-Familiar), and $0.23 \pm 0.035$ (Trained-Novel). ${ }^{* \star \star} P<0.001 . n=3$ males and 3 females per condition. Note $y$-axis scales in $C$ are different.

DMSO-infused condition (CMM: $P=1$ and $P=1$, for Rapamycin and SC79, respectively; NCM: $P=1$ and $P=1$, for Rapamycin and SC79, respectively).

\section{Experiment 3: the duration of song training negatively correlates with the molecular response after reexposure to familiar song}

To further understand what the implications of Rapamycinlowered pS6 levels upon reexposure to the training song might be, we asked if the duration of learning experience corresponded with levels of mTOR activation. There is not relevant precedence for mTOR in nonassociative learning paradigms, but previous experiments have associated higher levels of ERK/ZENK with brain areas actively engaged in learning processes (Bozon et al. 2003; Sweatt 2004; Thomas and Huganir 2004; Wang et al. 2004). Our $3 \mathrm{~h}$ of training song experience resulted in levels of ZENK and mTORC1 activation in the Trained-Familiar group that are midway between those of the Trained-Silence and Trained-Novel groups, suggesting that this experience supports incomplete habituation. To assess this possibility, in this experiment, we reduced $(1.5 \mathrm{~h})$ and extended $(6 \mathrm{~h}$ or 2 blocks of $3 \mathrm{~h}(2 \times 3 \mathrm{~h}))$ the training experience to test for increased and diminished molecular signaling responses, respectively, in the Trained-Familiar condition (Fig. 2). Immunoblots showed that birds who experienced a total of $6 \mathrm{~h}$ of training song had lower pERK/ERK and pS6/S6 levels in the auditory forebrain than those who were trained with $3 \mathrm{~h}$ of song playbacks. For pS6/S6, the $3 \mathrm{~h}$ levels are 3.6- and 2.8-fold greater than the $2 \times 3 \mathrm{~h}$ and $6 \mathrm{~h}$ training playback conditions, respectively, and for pERK/ERK, the $3 \mathrm{~h}$ levels are 2.8- and 1.9-fold greater than the $2 \times 3 \mathrm{~h}$ and $6 \mathrm{~h}$ training playback conditions, respectively. Further, birds in the Trained-Familiar groups who heard a total of $6 \mathrm{~h}$ of training song playbacks showed molecular responses no greater than those in the Trained-Silence condition (Fig. 5A, B). Birds who experienced $3 \mathrm{~h}$ of training song had average response levels intermediate between those measured in birds trained with $1.5 \mathrm{~h}$ or $6 \mathrm{~h}$ of song, although this was obvious for pERK/ERK only (Fig. 5A,B). Here, due to animal numbers, we relied on descriptive assessments to show that the general trend was for increased exposure to the training song to result in decreased levels of ERK and mTOR activation in the auditory forebrain upon presentation of the familiar song. We then used this evidence to pursue statistical testing of the combined effect of Rapamycin and training experience on mTOR activation in Experiments 4 and 5.

\section{Experiment 4: Rapamycin and extended training experience lower $\mathrm{mTORCl}$ activation levels}

Experiments 2 and 3 independently showed that $6 \mathrm{~h}$ of song training, and $3 \mathrm{~h}$ of training song experience combined with Rapamycin, reduced the level of mTORC1 activation in response to hearing playbacks of the familiar song, suggesting that Rapamycin enhances or accelerates habituation, as assessed by pS6 levels. To confirm this effect within the same experiment, and with sufficient power for statistical testing, we immunohistochemically assayed pS6+/S6+ cell densities in birds from three conditions: $3 \mathrm{~h}$ Trained-Familiar with DMSO, $6 \mathrm{~h}$ Trained-Familiar with DMSO, and $3 \mathrm{~h}$ Trained-Familiar with Rapamycin (Fig. 2, 5C). In both $\mathrm{CMM}$ and NCM, there was a significant effect of condition (CMM: $\quad F_{(2,24)}=32.45, \quad P=1.5 \mathrm{E}^{-7} ; \quad \mathrm{NCM}: \quad F_{(2,24)}=14.59, \quad P=$ $0.00007)$. In both brain regions, post hoc Bonferroni tests confirmed that Rapamycin infusion significantly lowered mTORC1 cascade activation in response to familiar song playbacks within the $3 \mathrm{~h}$ training condition (CMM: $P=2.1 \mathrm{E}^{-7}$; NCM: $P=0.00006$ ). 


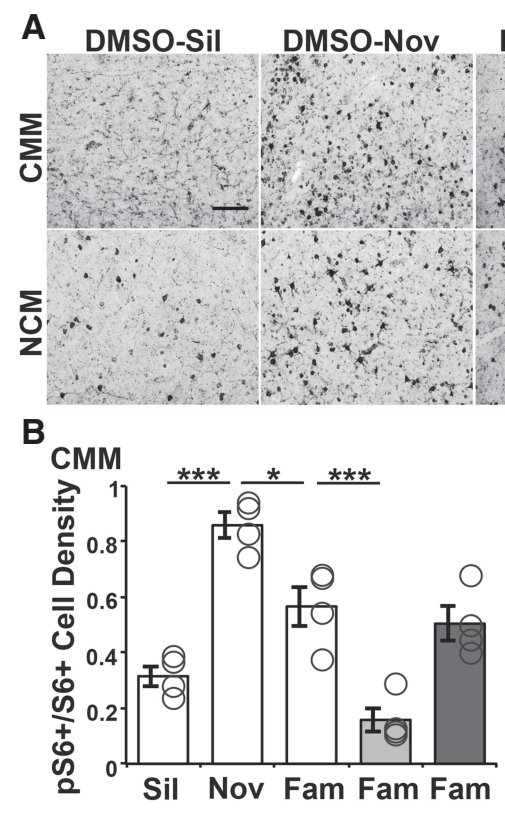

DMSO-Fam

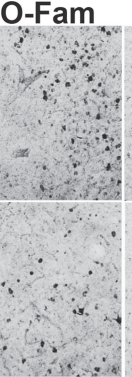

Rapa-Fam

NCM
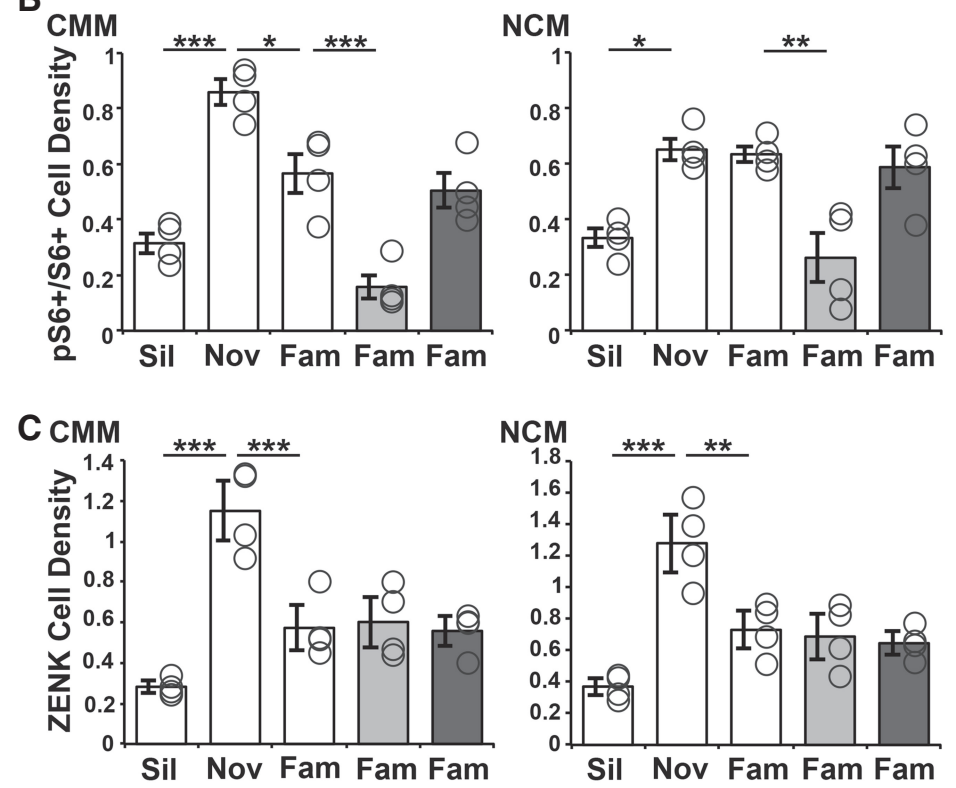

Figure 4. Inhibition, but not constitutive activation, of mTOR signaling during training specifically alters the pS6 levels in response to familiar song playbacks (Experiment 2). (A) Representative highmagnification images of pS6+ cells in the CMM and NCM of adult birds from each experimental condition. Images shown are from a mix of males and females. Scale bar $=100 \mu \mathrm{m}$. (B) pS6+/S6+ cell density ratios in the CMM (left) and NCM (right). CMM group means \pm SEM: $0.32 \pm 0.036$ (DMSO-Sil), $0.86 \pm 0.46$ (DMSO-Nov), $0.57 \pm 0.07$ (DMSO-Fam), 0.16 \pm 0.043 (Rapa-Fam), and $0.5 \pm$ 0.062 (SC79-Fam). NCM group means \pm SEM: $0.33 \pm 0.033$ (DMSO-Sil), $0.65 \pm 0.038$ (DMSO-Nov), $0.63 \pm 0.029$ (DMSO-Fam), $0.26 \pm 0.087$ (Rapa-Fam), and 0.59 \pm 0.075 (SC79-Fam). (C) Dysregulation of mTOR signaling during song playback training sessions does not alter ZENK induction patterns after familiar song exposure. Hippocampus-normalized ZENK-positive (ZENK+) cell density in the CMM (left) and NCM (right). CMM group means \pm SEM: $0.28 \pm 0.03$ (DMSO-Sil), $1.15 \pm 0.15$ (DMSO-Nov), $0.57 \pm 0.11$ (DMSO-Fam), $0.6 \pm 0.13$ (Rapa-Fam), and 0.56 \pm 0.074 (SC79-Fam). NCM group means \pm SEM: $0.37 \pm 0.054$ (DMSO-Sil), $1.28 \pm 0.19$ (DMSO-Nov), $0.73 \pm 0.12$ (DMSO-Fam), $0.69 \pm 0.15$ (Rapa-Fam), and $0.65 \pm 0.072$ (SC79-Fam). Bars represent the experimental condition mean \pm SEM. Open circles denote the individual birds in each experimental group. (Sil) TrainedSilence, (Fam) Trained-Familiar, (Nov) Trained-Novel. ${ }^{*} P<0.05,{ }^{* \star} P<0.005$, and ${ }^{* \star *} P<0.001$, between indicated groups. $n=2$ males and 2 females per group.

Likewise, among the DMSO-treated birds, $6 \mathrm{~h}$ of training song playbacks significantly reduced mTORC1 activity as compared with $3 \mathrm{~h}$ of training (CMM: $P=9.58 \mathrm{E}^{-6}$; NCM: $\left.P=0.004\right)$. $\mathrm{pS} 6+/ \mathrm{S} 6+$ cell densities in birds who experienced $6 \mathrm{~h}$ of training song playbacks and DMSO infusion were not significantly different than those in the 3 h Trained-Familiar with Rapamycin condition (CMM: $P=0.36$; NCM: $P=0.32$ ).

\section{Experiment 5: Rapamycin does not prevent mTORCl activation $24 \mathrm{~h}$ later}

An alternative, methodological, explanation to the Experiment 4 finding that $3 \mathrm{~h}$ of training song with Rapamycin results in the same, low level of mTORC1 activation after hearing familiar song as $6 \mathrm{~h}$ of training song is that Rapamycin caused a longterm nonselective disruption in mTORC1 activation. To verify that infusion of Rapamycin does not continue to prevent mTOR activation in response to song playbacks $24 \mathrm{~h}$ later, we conducted a control experiment in which birds in the Trained-Silence and Trained-Novel conditions received either Rapamycin or DMSO infusions prior to $3 \mathrm{~h}$ of training song playbacks (Fig. 2). There was a significant effect of song playback. pS6+l S6+ cell densities were higher in both Trained-Novel groups, when compared with the drug-matched Trained-Silence groups (CMM: $F_{(1,16)}=29.5, \quad P=5 \mathrm{E}^{-5}$; NCM: $\left.\quad F_{(1,16)}=19.2, P=4.7 \mathrm{E}^{-4}\right)$. There was no effect of Rapamycin compared to DMSO on the level of pS6+/S6+ cell density after playbacks of novel song (CMM: $F_{(1,16)}=3.1 \mathrm{E}^{-3}, P=0.69 ;$ NCM: $F_{(1,16)}=$ $\left.5.8 \mathrm{E}^{-3}, P=0.94\right)$. These data confirm that the mechanisms necessary for songinduced mTORC1 signaling are preserved $24 \mathrm{~h}$ after local Rapamycin infusions.

\section{Discussion}

The ability to learn individual songs is important to guide social behaviors in colonial-living zebra finches, and shares essential features with habituation. Prior understanding of the molecular mechanisms underlying this type of learning has essentially been limited to the ERK/ ZENK signaling cascade. The current studies focusing on patterns of mTOR activation expose complexity in the molecular processes associated with adult song recognition learning.

Several results are consistent with the possibility that mTORC1 is a molecular mechanism for nonassociative song learning. The relative levels of pS6 in $\mathrm{CMM}$ and $\mathrm{NCM}$ of unmanipulated and vehicle-infused Trained-Silence, -Novel, -Familiar birds mirrored the response patterns typical of habituation (Thompson and Spencer 1966; Mello et al. 1995; Dong and Clayton 2008; Dong et al. 2009; Rankin et al. 2009). mTORC1 inhibition during the training experience significantly altered the subsequent response to hearing that song again, which was not explained by a nonselective effect of the drug $24 \mathrm{~h}$ later. The relative magnitude of pERK and pS6 response to the familiar song depended on the extent of training song experience, adding evidence that mTORC1 activation reflects underlying processes of nonassociative learning.

However, several of our findings were unexpected, and raise new questions about potential mechanisms of song recognition learning. For example, inhibition, but not constitutive activation, of mTOR signaling during training song experience significantly altered the response to familiar song $24 \mathrm{~h}$ later. SC79 infusions to the adult auditory forebrain do enhance mTOR activation levels in the 


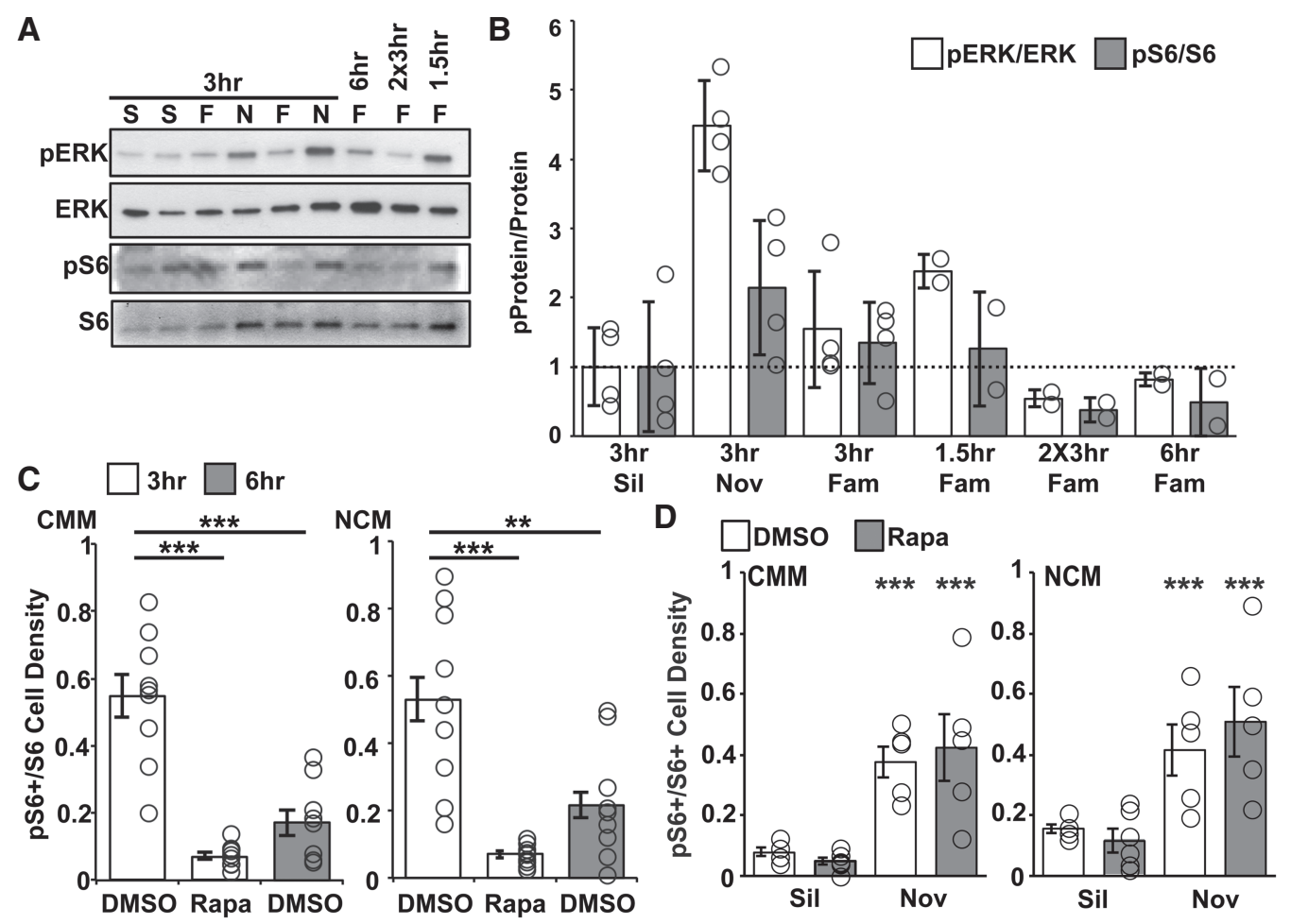

Figure 5. Inhibition of mTOR signaling during training lowers the pS6 response to familiar song playbacks (Experiments 3,4 , and 5$)(A)$, Immunoblot of pERK, total ERK, pS6, and total S6 in the auditory forebrain after a period of silence (S), and in response to novel $(\mathrm{N})$ and familiar (F) song playbacks after the following training periods: $3 \mathrm{~h}, 6 \mathrm{~h}, 2 \times 3 \mathrm{~h}$, and $1.5 \mathrm{~h}$. (B) Quantification of the normalized levels of pERK and pS6 detected via immunoblot. Phosphorylated/total protein levels were normalized to that of the Silence (Sil) controls (dotted line). White bars $=p E R K / E R K ; ~ g r a y ~ b a r s=p S 6 / S 6$. Bars represent the experimental condition mean \pm SD. Open circles denote the individual birds in each condition. pERK/ERK means \pm SD: $1 \pm 0.56$ ( $3 \mathrm{~h}$ Trained-Sil), $4.49 \pm 0.66$ ( $3 \mathrm{~h}$ Trained-Nov), $1.54 \pm 0.84$ ( $3 \mathrm{~h}$ Trained-Fam), $2.38 \pm 0.25(1.5 \mathrm{~h}$ Trained-Fam $), 0.54 \pm 0.13(2 \times 3 \mathrm{~h}$ Trained-Fam $)$, and $0.82 \pm 0.096(6 \mathrm{~h}$ Trained-Fam). pS6/S6 means \pm SD: $1 \pm 0.94$ (3 h Trained-Sil), $2.14 \pm 0.97$ (3 h Trained-Nov), $1.35 \pm 0.59(3 \mathrm{~h}$ Trained-Fam), $1.26 \pm 0.83(1.5 \mathrm{~h}$ Trained-Fam), $0.38 \pm 0.17(2 \times 3 \mathrm{~h}$ Trained-Fam), and $0.49 \pm 0.49(6 \mathrm{~h}$ Trained-Fam. $n=4$ ( $3 \mathrm{~h}$ Sil, Nov, Fam), $n=2(1.5 \mathrm{~h}, 6 \mathrm{~h}$, and $2 \times 3 \mathrm{~h}$ Fam). (C) pS6+/S6+ cell density ratios in the CMM (left) and NCM (right) after playbacks of familiar song (Fam) following training experiences of either 3 or $6 \mathrm{~h}$. White bars $=3 \mathrm{~h}$; gray bars $=6 \mathrm{~h}, n=9$ per group ( 5 females and 4 males). (D) pS6+/S6+ cell density ratios in the CMM (left) and NCM (right) of trained birds following either a period of silence (Sil) or after playbacks of Novel song (Nov). White bars = DMSO; gray bars $=$ Rapa. $n=4$ (DMSO-Sil), 6 (Rapa-Sil), and 5 (for both DMSO-Nov and Rapa-Nov). For both $C$ and $D$, bars represent the experimental condition mean \pm SEM. Open circles denote the individual birds in each experimental group. ${ }^{* *} P<0.01$, when compared with $3 \mathrm{~h} \mathrm{DMSO}$; ${ }^{* *} P<0.001$, when compared with $3 \mathrm{~h}$ DMSO $(C)$, or with drug-matched Sil groups $(D)$.

absence of song playbacks, but perhaps in combination with a song stimulus, we do not see further enhancements due to a ceiling effect (Ahmadiantehrani and London 2017). The effect of Rapamycin was in the opposite direction than expected, suggesting that mTORC1 inhibition enhances or accelerates habituation. These findings were surprising because in juvenile zebra finches, both constitutive activation and inhibition of mTORC1 in the auditory forebrain disrupted developmental song learning, and in associative learning paradigms in other models, balanced mTOR signaling is considered essential for learning and memory-both too much and too little activation is detrimental (Hoeffer and Klann 2010; Ahmadiantehrani and London 2017). Rapamycin can improve cognitive performance in clinical conditions where its autophagy function clears pathological protein aggregations (Bove et al. 2011; Talboom et al. 2015). In associative learning and memory paradigms, however, evidence is overwhelming that mTOR inhibition diminishes performance, perhaps because it prevents mTORC1-mediated translation of specific proteins that support synaptic plasticity (Parsons et al. 2006; Blundell et al. 2008; Belelovsky et al. 2009; Gafford et al. 2011; Stoica et al. 2011; Santini et al. 2014). mTORC1 integrates multiple upstream signals. Thus, it is possible that over the course of maturation, alterations in, for example, receptor subtypes, could explain the distinct effects of Rapamycin and SC79 in juvenile compared to adult auditory forebrain. It is also possible that the opposite direction of Rapamycin's effect on nonassociative learning compared to associative learning is due to our use of avian, rather than mammalian species. This is an unlikely explanation because core elements of the mTORC1 cascade are evolutionarily conserved (Fig. 1; van Dam et al. 2011). This is one of the few studies that bidirectionally manipulated mTOR signaling within the same learning paradigm, and the first we know of in a nonassociative context (Lana et al. 2017). Additional studies will therefore be required to understand why the drugs have distinct effects in this adult song recognition paradigm compared to juvenile tutor song memorization situations.

Additionally, our comparison of mTOR and ZENK in auditory forebrain reveals further questions about the possible molecular mechanisms of habituation. Until now, the ERK/ZENK signaling cascade served as the molecular exemplar for habituation response profiles (Mello et al. 1995; Cheng and Clayton 2004; Dong and Clayton 2008). We show here that in unmanipulated birds, mTORC1 activation patterns also show the expected profiles of habituation. Rapamycin during training song experience, however, altered our readout of mTORC1 signaling, pS6, but not the readout of ERK signaling, ZENK, in the Trained-Familiar condition. Rapamycin is highly selective for mTORC1, and the current data indicate no direct effect of the drug on ERK signaling (Hietman et al. 
1991; Mendoza et al. 2011). However, the incongruent molecular responses upon reexposure to the training song complicate interpretation of the efficacy of nonassociative learning. It may be that ERK and mTOR signaling encode distinct components of habituation, or that one of the cascades, despite displaying the expected pattern of activation after novel and familiar experiences, are not required for habituation. In the future, it would be interesting to understand the extent of cellular overlap between mTOR and ERK activation during training song playbacks and reexposure. There is growing understanding that specific cellular activation networks may be central features of learning and memory, and pS6 is present in clustered subsets of auditory forebrain cells compared to the widespread distributions of total S6 and ZENK (Frey and Morris 1997; Rogerson et al. 2014). A behavioral measure unaffected by cannulation procedures is necessary to draw causal conclusions about the relationship between molecular cascade activation and learning outcomes (Dong and Clayton 2008). Future efforts to develop a suitable measure will be important for deeper understanding of the complexity of specific molecular processes underlying habituation in adult songbirds.

Consideration of the anatomical pattern of mTOR activation provides another indication that processes for habituation may not be simple. In adults, song playback experience regulates molecular activation in two regions of the auditory forebrain, NCM and CMM (Mello et al. 1992, 1995; Mello and Clayton 1994; Dong and Clayton 2008; Dong et al. 2009; London et al. 2009 but see Horita et al. 2010). CMM and NCM likely have distinct yet complementary functions in processing complex auditory stimuli such as song (Mello et al. 1995; Vates et al. 1996; Gentner et al. 2004; Dong and Clayton 2008; Woolley and Doupe 2008). Across the current experiments, pS6/S6 levels in the Trained-Novel condition were significantly greater than in the Trained-Familiar condition in CMM, but not NCM. Rapamycin affected the response to familiar song equivalently in both regions, and comparisons of Trained-Novel pS6/S6 levels after Rapamycin were also indistinguishable. Thus NCM and CMM are equally sensitive to, and recover from, mTOR perturbation during training, but CMM shows a more graded readout of song familiarity than NCM. This is in contrast to measures of ERK/ZENK, which suggest that NCM is more involved in song novelty than CMM (Gentner et al. 2004; Woolley and Doupe 2008). Song is a complex communication signal, and the functional relationship between auditory forebrain regions is incompletely understood. As is well-appreciated in other learning systems, a single molecular cascade rarely explains the entirety of required neural processing. It is likely that here, too, multiple cascades provide dissociable contributions to recognition learning, underscoring the need for additional investigation into molecular mechanisms for habituation.

Combined, these results illustrate that complex sets of molecular mechanisms may underlie a form of nonassociative learning, adult song recognition learning. Indications from unmanipulated birds are that mTORC1 and ERK/ZENK are involved in song habituation, but mTOR manipulations reveal distinct regulation. This forms the foundation for future investigations altering the conditions of training song presentation with combinations of molecular disruptions. Development of an alternative to the existing behavioral assay will be instrumental for future investigations, but the current studies provide a platform to advance investigations into the complexity of molecular mechanisms of habituation in an ethologically relevant model for habituation.

\section{Materials and Methods}

\section{Experimental animals}

All procedures were conducted in accordance with the National Institute of Health guidelines for the care and use of animals for ex- perimentation, and were approved by the University of Chicago Institutional Animal Care and Use Committee (ACUP \#72220). All zebra finches were housed on a $14 \mathrm{~h}: 10 \mathrm{~h}$ light:dark cycle, with seed and water provided ad libitum. Experimental adults were raised normally in flight aviaries. To avoid using adults in different breeding or parenting statuses, they were segregated into single-sex cages in rooms housing both sexes at least $2 \mathrm{wk}$ prior to experiments. A unique set of birds was used for each experimental question, as detailed below; each experiment was analyzed independently to mitigate possible batch effects.

\section{Identification of $\mathrm{mTORCl}$ core proteins}

Adult males and females ( $n=4$ per sex) were retrieved from singlesex housed cages and, without any manipulation, the auditory forebrains were rapidly dissected, flash frozen on dry ice and stored at $-80^{\circ} \mathrm{C}$ until processing (Fig. 3B; immunoblot procedure is below).

\section{Adult song recognition learning paradigms}

On Day 1, adults were individually placed into acoustic isolation chambers, where they remained for the duration of the paradigm. Approximately $16 \mathrm{~h}$ later, on Day 2, all birds heard training playbacks of one of two songs, ZF101 or R6, which were recorded from birds in Dr. Susan Volman's laboratory at Ohio State University $\sim 20$ yr ago and were thus initially novel to all subjects (Stripling et al. 1997). During training song playbacks, one song bout ( $2 \mathrm{sec}$ in duration) was repeated every $10 \mathrm{sec}$; the same interstimulus interval was used for all variations of the habituation experience. Twenty-four hours after initiation of Day 2 training song playbacks, birds were either left in silence (Trained-Silence), presented with playbacks of the Day 2 training song (TrainedFamiliar), or presented with playbacks of the nontraining song (Trained-Novel). ZF101 and R6 playbacks were counterbalanced across birds and conditions. On Day 3, birds experienced $30 \mathrm{~min}$ of song playbacks, and brains were collected immediately afterwards for either immunohistochemical or immunoblot analysis. In all experiments with birds in the Trained-Silence condition, these individuals were collected interleaved between birds collected after song playbacks, no more than 20 min before or after a Trained-Novel or Trained-Familiar bird.

Experiments used varying conditions and song playback durations for Day 2 training (Fig. 2). To assess mTORC1 activation in response to song playbacks in Experiment 1, nonmanipulated birds experienced $3 \mathrm{~h}$ of Day 2 song playback, with $n=3$ per Sex for all Playback conditions (Trained-Silence, Trained-Novel, Trained-Familiar). One, $3 \mathrm{~h}$ playback session is sufficient for measurable behavioral and neural habituation (Chew et al. 1995; Mello et al. 1995; Stripling et al. 1997, 2003; Cheng and Clayton 2004; Dong and Clayton 2008; Dong et al. 2009). Experiment 2 tested how mTOR disruption during training song experience altered molecular song recognition measures. Birds in this experiment ( $n=2$ per Sex for each Playback condition) were bilaterally infused (details below) with drug or DMSO vehicle prior to $3 \mathrm{~h}$ Day 2 song playbacks. DMSO-infused birds experienced Novel, Familiar, and Silence on Day 3; Drug-infused birds were all in the Trained-Familiar Playback condition. Experiment 3 aimed to determine if the levels of Day 3 mTORC1 activation reflected the duration of training song experience on Day 2. Unmanipulated birds therefore experienced 1.5, 3, $6 \mathrm{~h}$, or two blocks of $3 \mathrm{~h}(2 \times 3 \mathrm{~h})$ song playbacks with $1.5 \mathrm{~h}$ of silence between on Day 2. $n=4(2$ males, 2 females) each for the $3 \mathrm{~h}$ Trained-Silence, -Familiar, and -Novel groups, and $n=2$ ( 1 male, 1 female) each for the $6 \mathrm{~h}, 2 \times 3$ $\mathrm{h}$, and $1.5 \mathrm{~h}$ Trained-Familiar groups. We combined conditions in Experiment 4 to directly and statistically compare the mTORC1 activation levels in vehicle-infused birds trained with either $3 \mathrm{~h}(3 \mathrm{~h}$ Trained-Familiar with DMSO; $n=9$ [ 4 males, 5 females] or $6 \mathrm{~h}$ of song playbacks $(6 \mathrm{~h}$ Trained-Familiar with DMSO; $n=9$ [ 4 males, 5 females]) to those who experience $3 \mathrm{~h}$ of song on Day 2 after Rapamycin infusion $(3 \mathrm{~h}$ Trained-Familiar with Rapa; $n=9$ [ 4 males, 5 females]). Experiment 5 verified that Rapamycin infusion on Day 2 did not nonselectively prevent 
mTORC1 responsivity to playbacks on Day 3 (Trained-Novel: Rapamycin $n=5$ ( 3 males, 2 females); DMSO $n=5$ ( 2 male, 3 females) and Trained-Silence: Rapamycin $n=6$ ( 3 males, 3 females); DMSO $n=4$ ( 2 males, 2 females)).

\section{Drug infusion procedures}

To neuroanatomically target drug and DMSO infusions, bilateral guide cannula (1 $\mathrm{mm}$ intercannula distance, cut to $2 \mathrm{~mm}$ length (cat \# C235G-1.0/SPC), Plastics One) were implanted into the auditory forebrain (coordinates $700 \mu \mathrm{m}$ anterior to $\mathrm{Y}_{0}$ (the anteriormost midline cerebellar boundary), $500 \mu \mathrm{m}$ lateral to midline, $45^{\circ}$ head angle) as previously described (Cheng and Clayton 2004; Dong and Clayton 2008; London and Clayton 2008). To verify positioning, immunostained sections containing cannula tracks were examined under a dissecting light microscope. For correlational analysis, sections were imaged and the medial-lateral, rostral-caudal, and dorsal-ventral positions of the cannula tip were calculated from the midline, or measured from the caudal boundary of the telencephalon or lateral ventricle, respectively (FIJI) (Schindelin et al. 2012). We obtained coordinates for both the right and left hemispheres.

For the drug-paired versions of the song recognition paradigm, birds were infused bilaterally with $0.5 \mu \mathrm{L} /$ hemisphere of Rapamycin ( $1 \mu \mathrm{g} / \mu \mathrm{L}$ in DMSO), SC79 (400 ng/ $\mu \mathrm{L}$ in DMSO), or undiluted DMSO (vehicle control) $30 \mathrm{~min}$ prior to the start of training song playbacks on Day 2. The 30 min provides a period of rest to minimize possible confounds of stress of handling and infusion with neural processing of the training song. Concentration of both drugs was determined with infusion timecourses to ensure that the drugs were active throughout the duration of training playbacks, including the 30 min period between infusion and playback designed to reduce the influence of handling stress (Ahmadiantehrani and London 2017). Here we added $400 \mathrm{ng} / \mu \mathrm{L}$ to the SC79 timecourse because our previous dose had a half-life of only $\sim 2.5 \mathrm{~h}$. Auditory forebrain infusions with $400 \mathrm{ng} / \mu \mathrm{L}$ of SC79 preserved a pS6+/S6+ ratio (0.76) after $4 \mathrm{~h}$ which was equivalent to the $\mathrm{pS} 6+/ \mathrm{S} 6+$ ratio obtained by novel song playback $(0.76)$, thus was used for these studies.

\section{Immunohistochemistry}

Birds were transcardially perfused with ice-cold 0.1 M PBS, followed by $4 \%$ paraformaldehyde in $0.025 \mathrm{M}$ PBS. Brains were dissected and post-fixed overnight at $4^{\circ} \mathrm{C}$. They were then embedded in gelatin ( $8 \%$ in $0.1 \mathrm{M}$ PBS) and fixed overnight at $4^{\circ} \mathrm{C}$. Gelatin-embedded brains were cryoprotected first in $15 \%$ and then $30 \%$ sucrose in $0.1 \mathrm{M}$ PBS. Brains were sectioned into $55 \mu \mathrm{m}$ sagittal sections in a series of three on a cryostat.

For each protein, we performed immunohistochemistry with all sections from a single series from midline to $\sim 990 \mu \mathrm{m}$ lateral for each bird to capture the extent of auditory forebrain, using both hemispheres (Cheng and Clayton 2004). After permeabilization with $0.3 \%$ Triton- $X$ in $0.1 \mathrm{M}$ PBS (30 min), endogenous peroxidases were exhausted with $2 \% \mathrm{H}_{2} \mathrm{O}_{2}$ in $0.1 \mathrm{M}$ PBS containing $0.05 \%$ Tween-20 (PBST) for 15 min. After extensive washes in PBST, sections were blocked with 3\% normal serum for $60 \mathrm{~min}$ at room temperature. Sections were incubated with primary antibodies overnight at $4^{\circ} \mathrm{C}$, followed by PBST washes and a 60 min roomtemperature incubation with biotinylated secondary antibodies. After washing with PBST, sections were incubated in avidin-biotin complex (Vectastain Elite ABC Kit; Vector Laboratories) for $30 \mathrm{~min}$ at room temperature. The peroxidase complex was visualized with DAB (Sigma) containing $0.003 \% \mathrm{H}_{2} \mathrm{O}_{2}$ in $0.1 \mathrm{M}$ PBS. Sections were then mounted, dehydrated, cleared, and coverslipped with Permount (Fisher Scientific).

The combination of antibodies and serum we used for immunohistochemistry were: S6: goat anti-S6 primary antibody (1:2000 in 1\% NHS-PBST; Santa Cruz Biotechnology \#E-13) or mouse anti-S6 primary antibody (1:250 in 1\% NHS-PBST; Cell Signaling Technology \#2317) blocked in normal horse serum (NHS), with a horse anti-goat IgG secondary antibody (1:500; Vector Laboratories \#BA-9500); pS6: rabbit anti-pS6 primary antibody (1:500 in
1\% NGS-PBST; Cell Signaling Technologies \#2211) blocked in normal goat serum (NGS), with a biotinylated goat anti-rabbit IgG secondary (1:500; Vector Laboratories \#BA-1000); ZENK: 1:1000 primary antibody in 1\% NGS-PBST (Santa Cruz Biotechnology \#sc-189) blocked in NGS, with a biotinylated goat anti-rabbit IgG secondary antibody (1:500; Vector Laboratories \#BA-1000).

\section{Immunohistochemistry imaging and quantification}

To assess the density of phosphorylated S6-positive (pS6+), total S6-positive (S6+), and ZENK-positive (ZENK+) immuno-stained cells, we captured images using the microscopes at the University of Chicago Integrated Light Microscopy Core Facility. For all brain sections, we obtained images that contain the secondary auditory forebrain regions (caudomedial nidopallium (NCM) and caudomedial mesopallium $(\mathrm{CMM})$ ) and primary auditory forebrain (Field $\mathrm{L}$ ) plus the adjacent hippocampus (HP) with a $4 \times$ objective. NCM and CMM in particular are known to show molecular responses to hearing conspecific songs, independent from induction by song production (Mello et al. 1992; Mello and Clayton 1994; Jarvis and Nottebohm 1997; Chirathivat et al. 2015). We used two microscopy systems: a Zeiss Axiovert $200 \mathrm{~m}$ microscope with a Zeiss Axiocam digital color CCD camera (Carl Zeiss Microscopy) running Slidebook 5.5 software (Intelligent Imaging Innovations), and an Olympus IX81 microscope (Olympus Corporation of the Americas) with a Hamamatsu Orca Flash 4.0 sCMOS camera (Hamamatsu Photonics) running Slidebook 5.0 software (Intelligent Imaging Innovations). For each experiment, all images used for quantification were captured with the same system.

For all images, we applied a threshold to exclude background staining in FIJI (Schindelin et al. 2012). We acquired particle count data (i.e., positively stained cells) for NCM, CMM, and HP; we observed very little staining in Field L (Fig. 3A). Neuroanatomical landmarks to identify each of these brain regions are visible; specific boundaries used to consistently quantify NCM, CMM, and HP across brain sections and individuals were informed by the Histological Atlas on the Zebra Finch Expression Brain Atlas (ZEBrA, Oregon Health and Science University: zebrafinchatlas. org). Positively stained cell counts were divided by the region of interest area to calculate a cell density measure. Captured images without any alteration were used for all immunohistochemical quantification, but were digitally altered for contrast clarity during figure preparation.

The HP does not display immediate early gene induction after song playbacks (Mello and Clayton 1994 but see Bailey et al. 2002), and thus can be useful to control for inter-section variation in immunostaining intensity. We did first verify that song playbacks do not alter HP cell density measures for pS6, S6, and ZENK in the current experiments. We then normalized CMM and NCM cell density measures to that of the HP from the same brain section. We calculated the mean HP-normalized pS6+ and S6+ cell densities separately for each bird, and used these to then calculate a mean pS6+/S6+. We used this bird average to represent the normalized level of S6 phosphorylation, and thus mTORC1 cascade activation, in NCM and CMM. For experience-dependent induction of ZENK protein, ZENK+ cell densities in the CMM and NCM were quantified and each normalized to the ZENK+ cell density of the HP.

\section{Immunoblots}

The auditory forebrain was bilaterally dissected as described previously (Cheng and Clayton 2004) then immediately flash frozen in tubes on dry ice, and stored at $-80^{\circ} \mathrm{C}$ until use. Ice-cold RIPA buffer (50 mM Tris-HCl, pH 7.4, 5 mM EDTA, 120 mM NaCl, 1\% NP-40, $0.1 \%$ deoxycholate, and $0.5 \%$ SDS) containing protease inhibitors was added directly to frozen tissues for mechanical homogenization and subsequent sonication. Lysates were allowed to rest on ice for $30 \mathrm{~min}$ before protein concentrations were measured using a NanoDrop 1000 spectrophotometer (Thermo Scientific). Fifteen $\mu \mathrm{g}$ of protein from each sample was resolved on a 4\%-20\% SDSPAGE gel (Tris-Glycine, BioRad), and transferred onto a PVDF membrane. To assay multiple proteins from the same biological samples and immunoblot, we cut the membrane horizontally, 
between the 150 and $100 \mathrm{kDa}$, and between the 50 and $37 \mathrm{kDa}$ molecular weight standards before proceeding with blocking (5\% nonfat dry milk (NFDM) in phosphate buffered saline (PBS) containing $0.1 \%$ Tween-20; PBST) for $30 \mathrm{~min}$ at room temperature, and primary antibody incubation prepared in 1\% NFDM in PBST, performed overnight at $4^{\circ} \mathrm{C}$. After three 10 min washes in PBST, membranes were incubated in HRP-conjugated secondary antibodies (antirabbit IgG, anti-goat IgG, and anti-mouse $\operatorname{IgG}$, all at 1:1000; Vector Laboratories, Burlingame, $\mathrm{CA}$ ) for $2 \mathrm{~h}$ at room temperature. Immunoreactivity was detected via an enhanced chemiluminescent reaction (Pierce ECL, ThermoFisher Scientific), and developed on autoradiography film (Amersham Hyperfilm ECL, GE Healthcare Life Sciences).

Primary antibodies used: rabbit IgG anti-mTOR (1:2000; EMD Millipore \#05-1592), rabbit IgG anti-S6K1 (1:2000, Cell Signaling Technology \#2708), goat IgG anti-S6 (1:5000, Santa Cruz Biotechnology \#E-13), mouse IgG anti-S6 (1:500, Cell Signaling Technology \#2317), rabbit anti-pS6 (1:2000, Cell Signaling Technology \#2211), rabbit anti-ERK (1:5000, Cell Signaling Technology \#4695), rabbit anti-pERK (1:1000, Cell Signaling Technology \#4370), mouse IgG anti-NeuN (1:10,000, EMD Millipore \#MAB377), mouse IgG anti-GAPDH (1:1000, EMD Millipore \#MAB374).

\section{Immunoblot analysis}

We digitally scanned the developed films for backgroundsubtracted densitometric quantification using FIJI (Schindelin et al. 2012). For total protein measurements, we outlined the band positioned at the expected protein size and acquired the mean gray value. We did the same measure to acquire background intensity value from the adjacent portion of the blot, then subtracted it to obtain an adjusted mean gray value for the protein band. For total protein analysis, densities were normalized to either NeuN or GAPDH loading controls. To acquire a measure of phosphorylated protein normalized to the level of total protein, we divided the intensity of the phosphorylated protein band by the intensity of the band for the appropriate total protein (e.g. pS6/ S6). Raw images of autoradiography films, without any alteration, were used for quantification; images were digitally altered for contrast clarity during figure preparation.

\section{Statistics}

StatPlus software (AnalystSoft) was used to run all statistical tests $(\alpha=0.05)$, including Student's $t$-test, one- and two-way Analysis of Variance (ANOVAs), and linear regressions. In the instance of significant main effects or interactions from ANOVAs, post hoc Bonferroni tests were used to identify significant pairwise differences.

\section{Acknowledgments}

The authors acknowledge the University of Chicago and the National Institute of Mental Health [T32MH020065].

\section{Competing interest statement}

The authors declare no competing financial interests.

\section{References}

Acharya KD, Veney SL. 2013. Sexually dimorphic expression and estradiol mediated up-regulation of a sex-linked ribosomal gene, RPS6, in the zebra finch brain. Dev Neurobiol 73: 599-608.

Ahmadiantehrani S, London SE. 2017. Bidirectional manipulation of mTOR signaling disrupts socially mediated vocal learning in juvenile songbirds. Proc Natl Acad Sci 114: 9463-9468.

Bailey DJ, Rosebush JC, Wade J. 2002. The hippocampus and caudomedial neostriatum show selective responsiveness to conspecific song in the female zebra finch. J Neurobiol 52: 43-51.

Belelovsky K, Kaphzan H, Elkobi A, Rosenblum K. 2009. Biphasic activation of the mTOR pathway in the gustatory cortex is correlated with and necessary for taste learning. J Neurosci 29: 7424-7431.
Blundell J, Kouser M, Powell CM. 2008. Systemic inhibition of mammalian target of rapamycin inhibits fear memory reconsolidation. Neurobiol Learn Mem 90: 28-35.

Bové J, Martinez-Vicente M, Vila M. 2011. Fighting neurodegeneration with Rapamycin: mechanistic insights. Nat Rev Neurosci 12: 437-452.

Bozon B, Davis S, Laroche S. 2002. Regulated transcription of the immediate-early gene Zif268: Mechanisms and gene dosage-dependent function in synaptic plasticity and memory formation. Hippocampus 12: 570-577.

Bozon B, Kelly A, Josselyn SA, Silva AJ, Davis S, Laroche S. 2003. MAPK, CREB and zif268 are all required for the consolidation of recognition memory. Philos Trans R Soc Lond B Biol Sci 358: 805-814.

Cammalleri M, Lütjens R, Berton F, King AR, Simpson C, Francesconi W, Sanna PP. 2003. Time-restricted role for dendritic activation of the mTOR-p70S6K pathway in the induction of late-phase long-term potentiation in the CA1. Proc Natl Acad Sci 100: 14368-14373.

Cheng HY, Clayton DF. 2004. Activation and habituation of extracellular signal-regulated kinase phosphorylation in zebra finch auditory forebrain during song presentation. J Neurosci 24: 7503-7513.

Chew SJ, Mello C, Nottebohm F, Jarvis E, Vicario DS. 1995. Decrements in auditory responses to a repeated conspecific song are long-lasting and require two periods of protein synthesis in the songbird forebrain. Proc Natl Acad Sci 92: 3406-3410.

Chirathivat N, Raja SC, Gobes SMH. 2015. Hemispheric dominance underlying the neural substrate for learned vocalizations develops with experience. Sci Rep 5: 11359.

Costa-Mattioli M, Monteggia LM. 2013. mTOR complexes in neurodevelopmental and neuropsychiatric disorders. Nat Neurosci 16: 1537-1543.

Dong S, Clayton DF. 2008. Partial dissociation of molecular and behavioral measures of song habituation in adult zebra finches. Genes Brain Behav 7: 802-809.

Dong S, Replogle KL, Hasadsri L, Imai BS, Yau PM, Rodriguez-Zas S, Southey BR, Sweedler JV, Clayton DF. 2009. Discrete molecular states in the brain accompany changing responses to a vocal signal. Proc Natl Acad Sci 106: 11364-11369.

Dugas-Ford J, Rowell JJ, Ragsdale CW. 2012. Cell-type homologies and the origins of the neocortex. Proc Natl Acad Sci 109: 16974-16979.

Fifield K, Hebert M, Angel R, Adamec R, Blundell J. 2013. Inhibition of mTOR kinase via Rapamycin blocks persistent predator stress-induced hyperarousal. Behav Brain Res 256: 457-463.

Fortress AM, Heisler JD, Frick KM. 2015. The mTOR and canonical Wnt signaling pathways mediate the mnemonic effects of progesterone in the dorsal hippocampus. Hippocampus 25: 616-629.

Frey U, Morris RG. 1997. Synaptic tagging and long-term potentiation. Nature 385: $533-536$.

Gafford GM, Parsons RG, Helmstetter FJ. 2011. Consolidation and reconsolidation of contextual fear memory requires mammalian target of Rapamycin-dependent translation in the dorsal hippocampus. Neuroscience 182: 98-104.

Gentner TQ, Hulse SH, Ball GF. 2004. Functional differences in forebrain auditory regions during learned vocal recognition in songbirds. J Comp Physiol A Neuroethol Sens Neural Behav Physiol 190: 1001-1010.

Giles AC, Rankin CH. 2009. Behavioral and genetic characterization of habituation using Caenorhabditis elegans. Neurobiol Learn Mem 92: $139-146$.

Gobes SM, Zandbergen MA, Bolhuis JJ. 2010. Memory in the making: localized brain activation related to song learning in young songbirds. Proc Biol Sci 277: 3343-3351.

Graber TE, McCamphill PK, Sossin WS. 2013. A recollection of mTOR signaling in learning and memory. Learn Mem 20: 518-530.

Hietman J, Movva NR, Hall MN. 1991. Targets for cell cycle arrest by the immunosuppressant Rapamycin in yeast. Science 253: 905-909.

Hoeffer CA, Klann E. 2010. mTOR signaling: at the crossroads of plasticity, memory and disease. Trends Neurosci 33: 67-75.

Horita H, Wada K, Rivas MV, Hara E, Jarvis ED. 2010. The dusp1 Immediate Early Gene is Regulated by Natural Stimuli Predominantly in Sensory Input Neurons. J Comp Neurol 518: 2873-2901.

Jarvis ED, Nottebohm F. 1997. Motor-driven gene expression. Proc Natl Acad Sci 94: 4097-4102.

Jo H, Mondal S, Tan D, Nagata E, Takizawa S, Sharma AK, Hou Q, Shanmugasundaram K, Prasad A, Tung JK, et al. 2012. Small molecule-induced cytosolic activation of protein kinase Akt rescues ischemia-elicited neuronal death. Proc Natl Acad Sci 109: 10581-10586.

Karten HJ. 2013. Neocortical Evolution: Neuronal Circuits Arise Independently of Lamination. Curr Biol 23: R12-R15.

Kelleher RJ, III, Govindarajan A, Tonegawa S. 2004. Translational regulatory mechanisms in persistent forms of synaptic plasticity. Neuron 44: 59-73.

Kruse AA, Stripling R, Clayton DF. 2004. Context-specific habituation of the zenk gene response to song in adult zebra finches. Neurobiol Learn Mem 82: $99-108$. 
Lana D, Di Russo J, Mello T, Wenk GL, Giovannini MG. 2017. Rapamycin inhibits mTOR/p70S6K activation in CA3 region of the hippocampus of the rat and impairs long term memory. Neurobiol Learn Mem 137: 15-26.

Laplante M, Sabatini DM. 2009. mTOR signaling at a glance. J Cell Sci 122: 3589-3594.

Leussis MP, Bolivar VJ. 2006. Habituation in rodents: a review of behavior, neurobiology, and genetics. Neurosci Biobehav Rev 30: 1045-1064.

Lin LC, Vanier DR, London SE. 2014. Social information embedded in vocalizations induces neurogenomic and behavioral responses. PLOS One 9: e112905.

London SE, Clayton DF. 2008. Functional identification of sensory mechanisms required for developmental song learning. Nat Neurosci 11: $579-586$.

London SE, Dong S, Replogle K, Clayton DF. 2009. Developmental shifts in gene expression in the auditory forebrain during the sensitive period for song learning. Dev Neurobiol 69: 437-450.

McKenzie TL, Hernandez AM, MacDougall-Shackleton SA. 2006. Experience with songs in adulthood reduces song-induced gene expression in songbird auditory forebrain. Neurobiol Learn Mem 86: 330-335.

Mello CV, Clayton DF. 1994. Song-induced ZENK gene expression in auditory pathways of songbird brain and its relation to the song control system. J Neurosci 14: 6652-6666.

Mello CV, Vicario DS, Clayton DF. 1992. Song presentation induces gene expression in the songbird forebrain. Proc Natl Acad Sci 89: 6818-6822.

Mello C, Nottebohm F, Clayton D. 1995. Repeated exposure to one song leads to a rapid and persistent decline in an immediate early gene's response to that song in zebra finch telencephalon. J Neurosci 15: 6919-6925.

Mendoza MC, Er EE, Blenis J. 2011. The Ras-ERK and PI3K-mTOR Pathways: Cross-talk and Compensation. Trends Biochem Sci 36: 320-328.

Parsons RG, Gafford GM, Helmstetter FJ. 2006. Translational control via the mammalian target of Rapamycin pathway is critical for the formation and stability of long-term fear memory in amygdala neurons. J Neurosci 26: 12977-12983.

Rankin CH, Abrams T, Barry RJ, Bhatnagar S, Clayton D, Colombo J, Coppola G, Geyer MA, Glanzman DL, Marsland S, et al. 2009. Habituation Revisited: An Updated and Revised Description of the Behavioral Characteristics of Habituation. Neurobiol Learn Mem 92: 135-138.

Richter JD, Klann E. 2009. Making synaptic plasticity and memory last: mechanisms of translational regulation. Genes Dev 23: 1-11.

Riebel K. 2009. Chapter 6 Song and Female Mate Choice in Zebra Finches: A Review. In Advances in the Study of Behavior, Vol 40, pp. 197-238.

Rogerson T, Cai DJ, Frank A, Sano Y, Shobe J, Lopez-Aranda MF, Silva AJ. 2014. Synaptic tagging during memory allocation. Nat Rev Neurosci 15: 157-169.
Santini E, Huynh TN, Klann E. 2014. Mechanisms of translation control underlying long-lasting synaptic plasticity and the consolidation of long-term memory. Prog Mol Biol Transl Sci 122: 131-167.

Schindelin J, Arganda-Carreras I, Frise E, Kaynig V, Longair M, Pietzsch T, Preibisch S, Rueden C, Saalfeld S, Schmid B, et al. 2012. Fiji: an open-source platform for biological-image analysis. Nat Methods $\mathbf{9}$ : 676-682.

Stoica L, Zhu PJ, Huang W, Zhou H, Kozma SC, Costa-Mattioli M. 2011. Selective pharmacogenetic inhibition of mammalian target of Rapamycin complex I (mTORC1) blocks long-term synaptic plasticity and memory storage. Proc Natl Acad Sci 108: 3791-3796.

Stripling R, Volman SF, Clayton DF. 1997. Response modulation in the zebra finch neostriatum: relationship to nuclear gene regulation. JNeurosci 17: 3883-3893.

Stripling R, Milewski L, Kruse AA, Clayton DF. 2003. Rapidly learned song-discrimination without behavioral reinforcement in adult male zebra finches (Taeniopygia guttata). Neurobiol Learn Mem 79: 41-50.

Sweatt JD. 2004. Mitogen-activated protein kinases in synaptic plasticity and memory. Curr Opin Neurobiol 14: 311-317.

Talboom JS, Velazquez R, Oddo S. 2015. The mammalian target of Rapamycin at the crossroad between cognitive aging and Alzheimer's disease. Npj Aging Mech Dis 1: 15008.

Thomas GM, Huganir RL. 2004. MAPK cascade signalling and synaptic plasticity. Nat Rev Neurosci 5: 173-183.

Thompson RF, Spencer WA. 1966. Habituation: a model phenomenon for the study of neuronal substrates of behavior. Psychol Rev 73: 16-43.

Tischmeyer W, Grimm R. 1999. Activation of immediate early genes and memory formation. Cell Mol Life Sci 55: 564-574.

van Dam TJP, Zwartkruis FJT, Bos JL, Snel B. 2011. Evolution of the TOR Pathway. J Molr Evol 73: 209-220.

Vates GE, Broome BM, Mello CV, Nottebohm F. 1996. Auditory pathways of caudal telencephalon and their relation to the song system of adult male zebra finches (Taenopygia guttata). J Comp Neurol 366: 613-642.

Wang JQ, Tang Q, Parelkar NK, Liu Z, Samdani S, Eun SC, Yang L, Mao L. 2004. Glutamate signaling to Ras-MAPK in striatal neurons: Mechanisms for inducible gene expression and plasticity. Mol Neurobiol 29: 1-14.

Wang Y, Brzozowska-Prechtl A, Karten HJ. 2010. Laminar and columnar auditory cortex in avian brain. Proc Natl Acad Sci 107: 12676-12681.

Woolley SC, Doupe AJ. 2008. Social Context-Induced Song Variation Affects Female Behavior and Gene Expression. PLoS Biol 6: e62.

Received February 6, 2018; accepted in revised form March 19, 2018. 


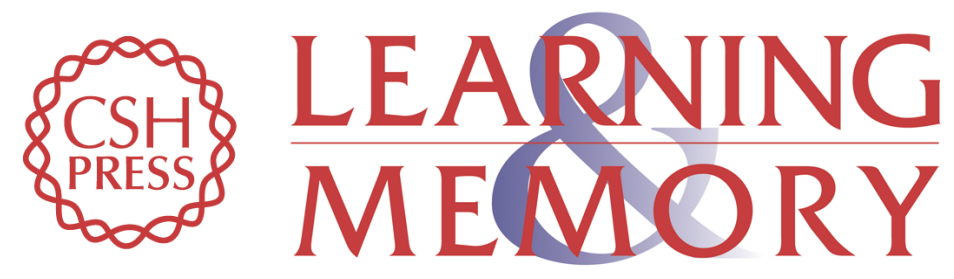

\section{A complex mTOR response in habituation paradigms for a social signal in adult songbirds}

Somayeh Ahmadiantehrani, Elisa O. Gores and Sarah E. London

Learn. Mem. 2018, 25:

Access the most recent version at doi:10.1101/Im.046417.117

\begin{aligned} & \hline References $\begin{array}{l}\text { This article cites } 63 \text { articles, } 20 \text { of which can be accessed free at: } \\ \text { http://learnmem.cshlp.org/content/25/6/273.full.html\#ref-list-1 }\end{array} \\ & \begin{array}{r}\text { Creative } \\ \text { Commons } \\ \text { License }\end{array} \begin{array}{l}\text { This article is distributed exclusively by Cold Spring Harbor Laboratory Press for the } \\ \text { first } 12 \text { months after the full-issue publication date (see } \\ \text { http://learnmem.cshlp.org/site/misc/terms.xhtml). After } 12 \text { months, it is available under } \\ \text { a Creative Commons License (Attribution-NonCommercial } 4.0 \text { International), as } \\ \text { described at http://creativecommons.org/licenses/by-nc/4.0/. }\end{array} \\ & \begin{array}{c}\text { Receive free email alerts when new articles cite this article - sign up in the box at the } \\ \text { top right corner of the article or click here. }\end{array} \\ & \begin{array}{c}\text { Service } \\ \text { terting }\end{array}\end{aligned}$ 